\title{
Stratigraphy, stable isotopes and salinity in multi-year sea ice from the rift area, south George VI Ice Shelf, Antarctic Peninsula
}

\author{
J.-L. Tison, \\ Faculté des Sciences - C.P. 160, Université Libre de Bruxelles, \\ 50 avenue Franklin Roosevelt, B-1050 Bruxelles, Belgium \\ E. M. MORRIS, \\ British Antarctic Survey, Natural Environment Research Council, Cambridge CB3 OET, England \\ R. Souchez, \\ Faculté des Sciences - C.P. 160, Université Libre de Bruxelles, \\ 50 avenue Franklin Roosevelt, B-1050 Bruxelles, Belgium \\ J. JOUZEL \\ Laboratoire de Géochimie Isotopique LOD YC/DPC, Centre d'Etudes Nucléaires de Saclay, \\ F-91191 Gif-sur-Yvette, France
}

\begin{abstract}
Results from a detailed profile in a $5.54 \mathrm{~m}$ multi-year sea-ice core from the rift area in the southern part of George VI Ice Shelf are presented. Stratigraphy, stable isotopes and $\mathrm{Na}$ content are used to investigate the growth processes of the ice cover and to relate them to melting processes at the bottom of the ice shelf.

The thickest multi-year sea ice in the sampling area appears to be second-year sea ice that has survived one melt season. Combined salinity/stable-isotope analyses show large-scale sympathetic fluctuations that can be related to the origin of the parent water. Winter accretion represents half of the core length and mainly consists of frazil ice of normal sea-water origin. However, five major dilution events of sea water, with fresh-water input from the melting base of the ice shelf reaching $20 \%$ on two occasions, punctuate this winter accretion. Two of them correspond to platelet-ice production, which is often related to the freezing of ascending supercooled water from the bottom of the ice shelf.

Brackish ice occurs between 450 and $530 \mathrm{~cm}$ in the core. It is demonstrated that this results from the freezing of brackish water (Jeffries and others, 1989) formed by mixing of normal sea water with melted basal shelf ice, with dilution percentages of maximum $80 \%$ fresh water.
\end{abstract}

\section{INTRODUCTION}

Stratigraphy and salinity profiles in multi-year sea ice have been measured by several authors in the last decade, both in the Arctic (mainly the northern Ellesmere Island area, Fram Strait and the Beaufort Sea; Schwarzacher, 1959; Cherepanov, 1966; Weeks and Ackley, 1986; Gow and others, 1987b; Meese, 1989) and the Antarctic (mainly in the McMurdo Sound area and in the Weddell Sea; Weeks and Ackley, 1986; Gow and others, 1987a Lange and others, 1989). However, these studies were mainly focused on drifting pack ice, the properties and formation mechanisms of which are often quite different from land-fast sea ice.

Combined salinity/stable-isotope analyses are less extensive in the literature but have also been undertaken in both polar regions. One major advantage of the method is that it allows the discrimination of different parentwater sources for the ice growth, as has been clearly demonstrated by previous authors (Friedman and others, 1961; Lyons and others, 1971; Gow and Epstein, 1972). Recently, a study by Jeffries and others (1989) has provided the first attempt to use the stable-isotope ratio ${ }^{18} \mathrm{O} /{ }^{16} \mathrm{O}$ as a tracer to detect fresh, brackish and sea- 


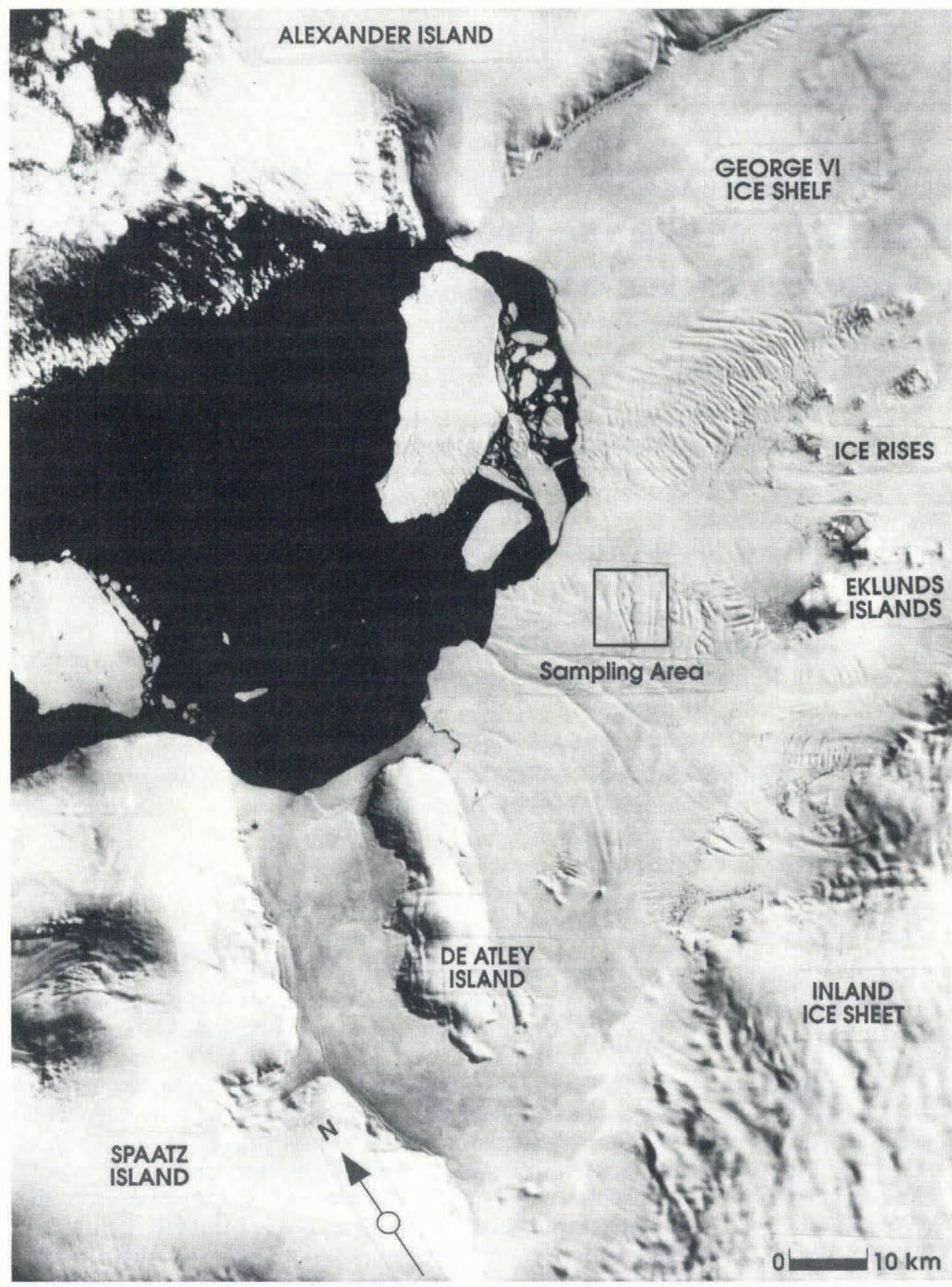

Fig. 1. Landsat image of southern George VI Ice Shelf (9 January 1973).

water origins in multi-year land-fast sea ice from the Arctic (north Ellesmere Island, Canadian Arctic). Brackish ice was found there in significant amounts.

This paper gives the results of a detailed textural, isotopic and chemical analysis performed on multi-year land-fast sea ice from the Antarctic Peninsula. The properties of the ice samples from the large rifts affecting the southern part of George VI Ice Shelf are related to the melting processes at the surface and at the bottom of the ice shelf.

\section{SAMPLING SITE AND ANALYTICAL PROCEDURE}

Ten sea-ice cores and two surface ice-shelf cores were retrieved from the major rift closest to the southern active border of George VI Ice Shelf (Fig. 1) as part of a joint
Belgian/British project in the 1987-88 British Antarctic Survey field programme.

Two major sets of large surface waves affect the George VI Ice Shelf surface where it thins in the southwestern part and where the main outlet flow of the ice shelf from the northeast meets the local southeasterly flow from the Plateau. One of these wave sets happens to be roughly parallel to the actively calving ice-shelf edge and so the troughs are preferred sites for the opening of major rifts where sea water reaches the surface. During the summer, open-water areas are located where troughs from each wave system meet. The remaining bottom surface of the rift is covered with sea ice of variable thickness $(1-5.5 \mathrm{~m})$. Away from the transverse depression, the rift borders turn into sharp cliffs about $20 \mathrm{~m}$ high. Firstyear sea ice started to cover the open water close to the sampling site at the end of February 1988. 


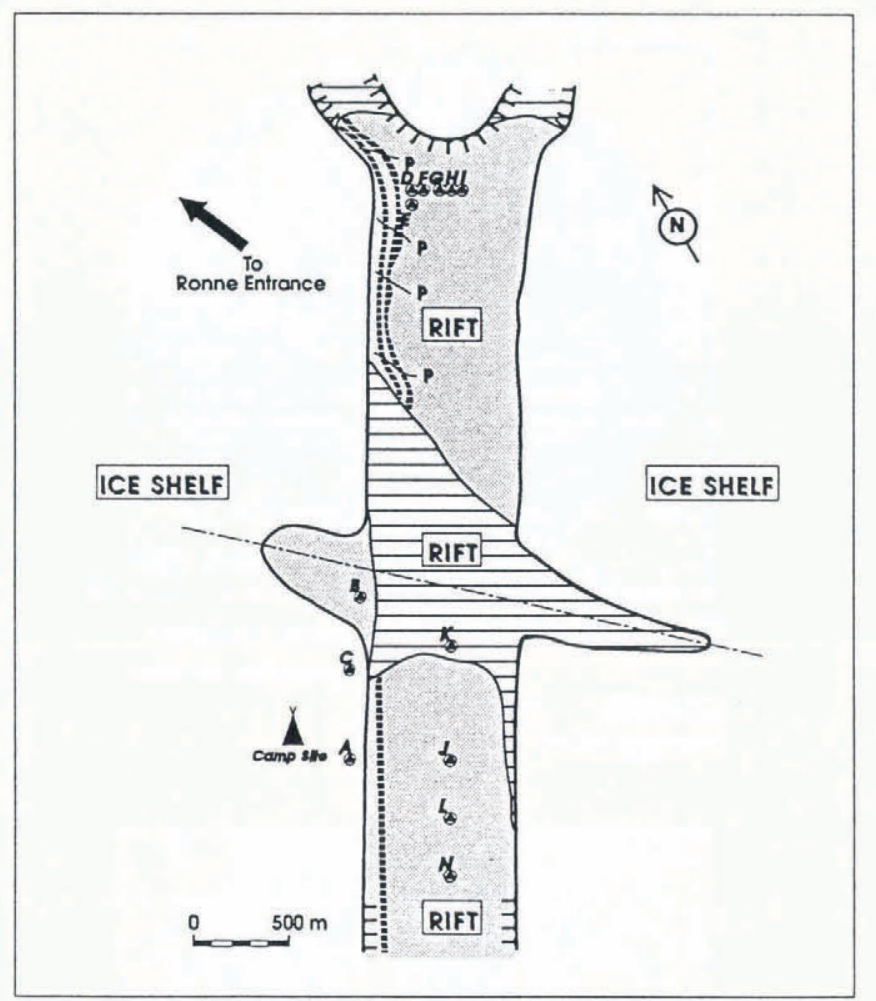

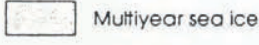

TTTT Clift

Depression in the Ice Shelf
Open woters covered by first - year sea ice
(February 1988)

1 Core location
Fig. 2. Sketch showing the location of the cores in the sampling area.

Two different sets of sea-ice cores were retrieved in the sampling area (Fig. 2). One set was collected along a longitudinal profile south of the open water where the sea-ice thicknesses varied from 0.97 to $2.57 \mathrm{~m}$ (cores J to $\mathrm{N}$ ) and the other set along a transverse profile a few kilometres to the north, where ice thicknesses fluctuated between 3.49 and $5.54 \mathrm{~m}$ (cores $\mathrm{F}$ to I). In addition, one core was sampled in the multi-year sea ice from the transverse depression (B) and another in the freshly formed first-year sea ice (K). Finally, the surface ice shelf was sampled in two different locations (cores A and C). As the main focus was to study multi-year sea ice, the thickest core $(\mathrm{H})$ has been selected for detailed analyses.

The cores were sampled with a PICO drill, transferred to plastic bags and stored below $-20^{\circ} \mathrm{C}$ in a small "sledge-fitting" freezer until transport by aircraft to Rothera base. At Rothera and aboard RRS Bransfield on the journey to the U.K., the cores were again stored in freezers at $-20^{\circ} \mathrm{C}$. The following analytical techniques were performed in the cold laboratory $\left(-25^{\circ} \mathrm{C}\right)$ in Brussels:

Ice texture: vertical thin sections were taken along the whole profile to estimate the proportion of the different sea-ice crystal types and to guide the isotopic sampling.

Sodium profile: for each individual part of the core, the entire outside part of the cylindrical core sample was trimmed off with a band saw to avoid contamination which may have occurred during sampling in the field and during transport. A $1 \mathrm{~cm}$ thick vertical slice was then cut through samples of $0.5 \mathrm{~cm}$ width using standard methods to reduce contamination to the noise level of the Perkin-Elmer atomic absorption spectrophotometry. A total of 1120 samples, regularly spaced throughout the core, have been measured for their $\mathrm{Na}$ content. Sodium will be used here as a "proxy" for the global salinity, bearing in mind that the ratio $\mathrm{Na}$ /global salinity is 0.3074 in the oceans and is independent of the salinity level for a large range of salinities (Riley and Skirrow, 1965), and that the same ratio is valid for sea ice as indicated by the dilution curves and statistical analyses performed by Meese (1989) on sea-ice samples from the Beaufort Sea.

Isotopic profiles: a second $1 \mathrm{~cm}$ thick vertical slice of each individual part of the core was sampled in selected spots for co-isotopic analysis of deuterium and oxygen-18 (120 samples). The small amounts of ice necessary for the mass-spectrometer measurements $(0.3 \mathrm{ml})$ were collected using a microtome, allowing precise location of the samples and detailed profiling where required. The massspectrometer analyses were performed at the Laboratoire de Géochimie Isotopique, Centre d'Etudes Nucléaires de Saclay, France.

HDO concentrations will be given hereafter in $\delta$ units calculated with respect to VSMOW (Vienna Standard Mean Ocean Water) expressed in parts per thousand (ppt), e.g.

$$
\delta \mathrm{D}=1000\left[\frac{R_{\mathrm{D} \text { sample }}-R_{\mathrm{D} \text { VSMOW }}}{R_{\mathrm{D} \text { vSMOW }}}\right]
$$

where $R_{\text {D sample }}$ and $R_{\text {D VSMow }}$ are the isotopic ratios of the sample and of the VSMOW, respectively. The accuracy of the measurments is $\pm 0.5 \%$ in $\delta \mathrm{D}$ and $\pm 10 \%$ in $\delta^{18} \mathrm{O}$.

\section{RESULTS AND DISCUSSION}

\section{General features of the core}

Figures 3 and 4 summarize the textural, isotopic and chemical characteristics of the core. An example of the different types of ice observed in the core, together with a brief description of their characteristics is shown in Figure 3. Figure 4 presents the combined sodium $/ \delta^{18} \mathrm{O}$ profile with depth. The symbols used for the different types of ice in this figure are defined in Figure 3 . $\mathrm{Na}$ values have been smoothed with a running mean on 11 values to dampen high-frequency fluctuations and obtain a resolution similar to that of the $\delta^{18} \mathrm{O}$ values. Two major observations can be made:

a. The core consists mainly of granular ice, which is esentially frazil ice, as will be discussed below. If we discard $100 \mathrm{~cm}$ of porous granular ice at the top, which is certainly, as will be shown later, not the result of water freezing, granular ice occurs in $74 \%$ of the core, columnar ice in $19.4 \%$ and needle-like ice (platelet ice as described by Lange and others (1989)) in 6.6\%. 


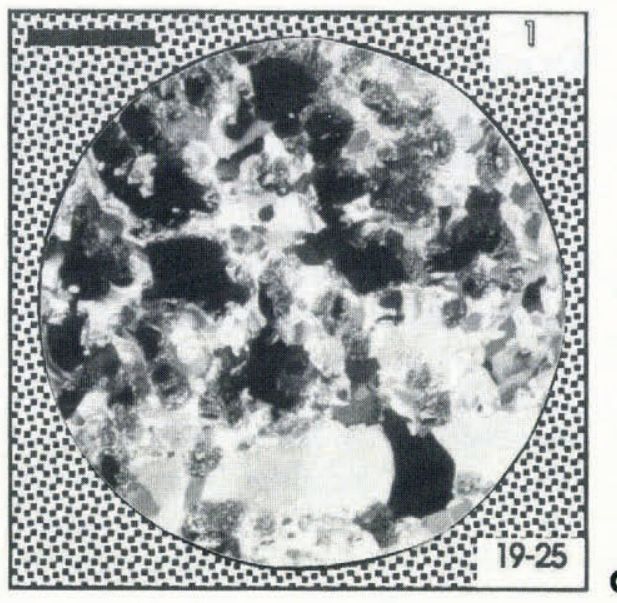

Texture : equigranular and porous

Crystals : polygonal with sharp contours Elongation: none

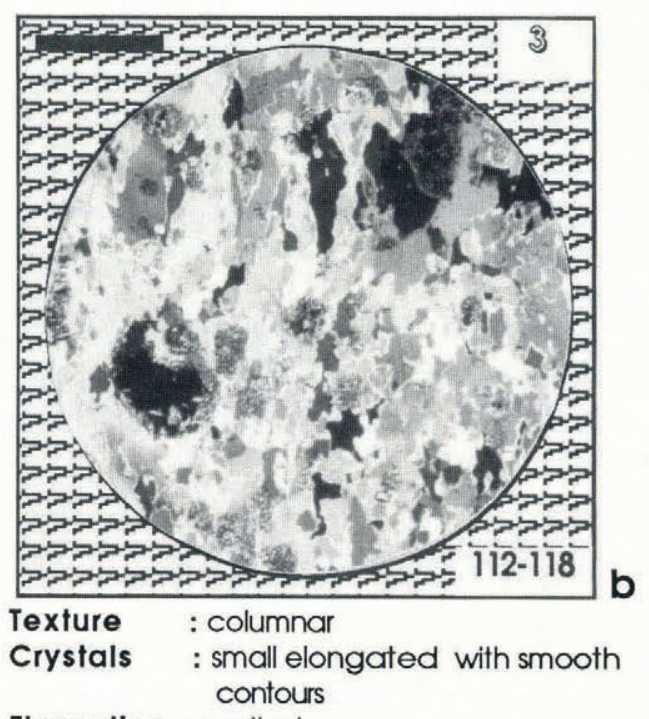

Elongation : vertical

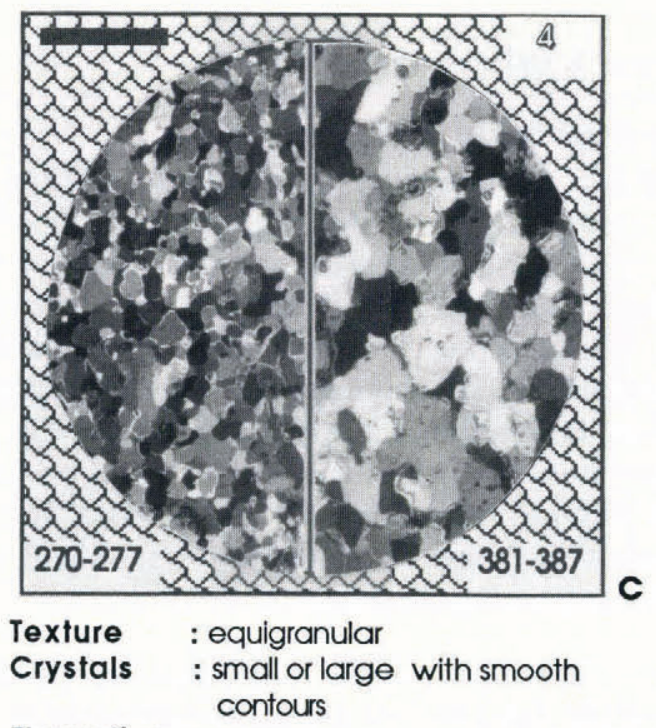

Elongation : none

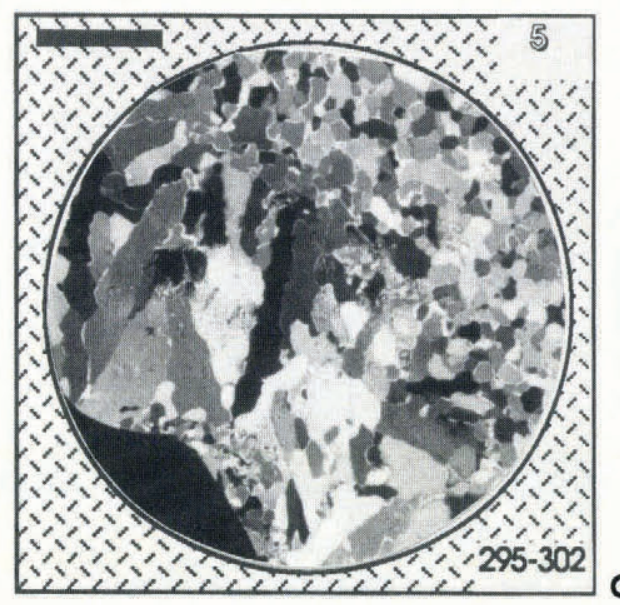

Texture : contact between platelets and an equigranular matrix

Crystals : needle-like

Elongation : oblique
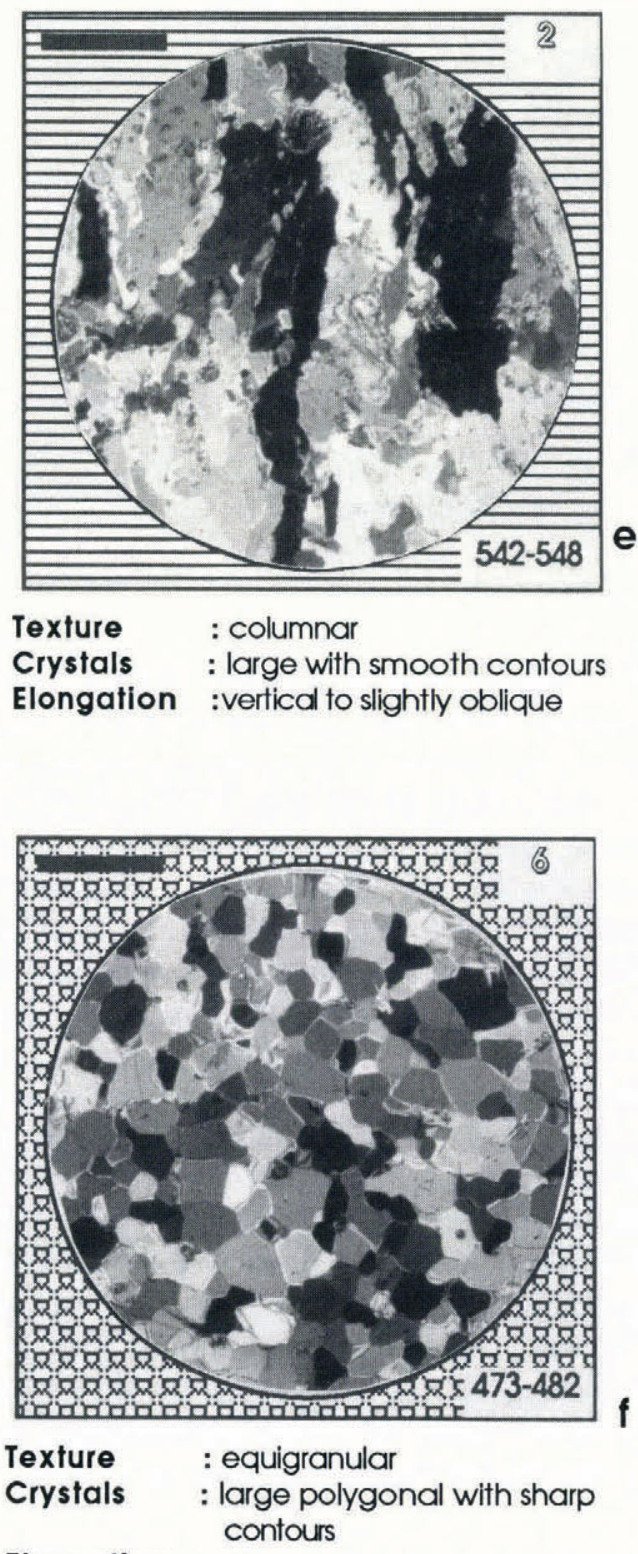

Elongation : none

Fig. 3. Textural characteristics of the main ice types in core H. The thin sections were prepared in the vertical plane. The symbols in the background and the numbers in the right upper corner are those used in Figure 4. The black scale is $1 \mathrm{~cm}$ long. The numbers in the lower corners give the location (in $\mathrm{cm}$ ) of the sections in the core. 
Tison and others: Stratigraphy, etc., in rift area of George VI Ice Shelf
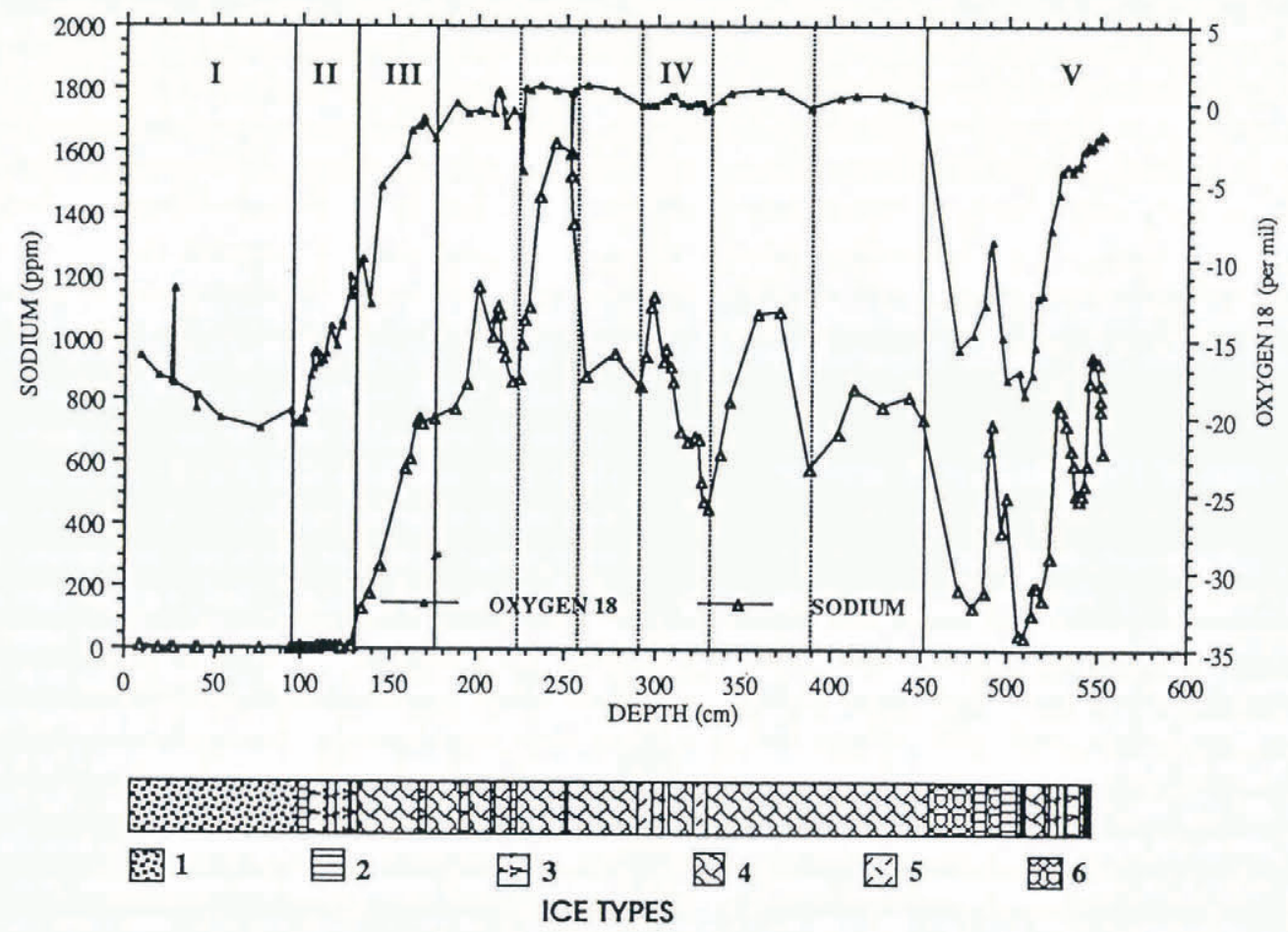

Fig. 4. Textural, isotopic and chemical characteristics of core $\mathrm{H}$.
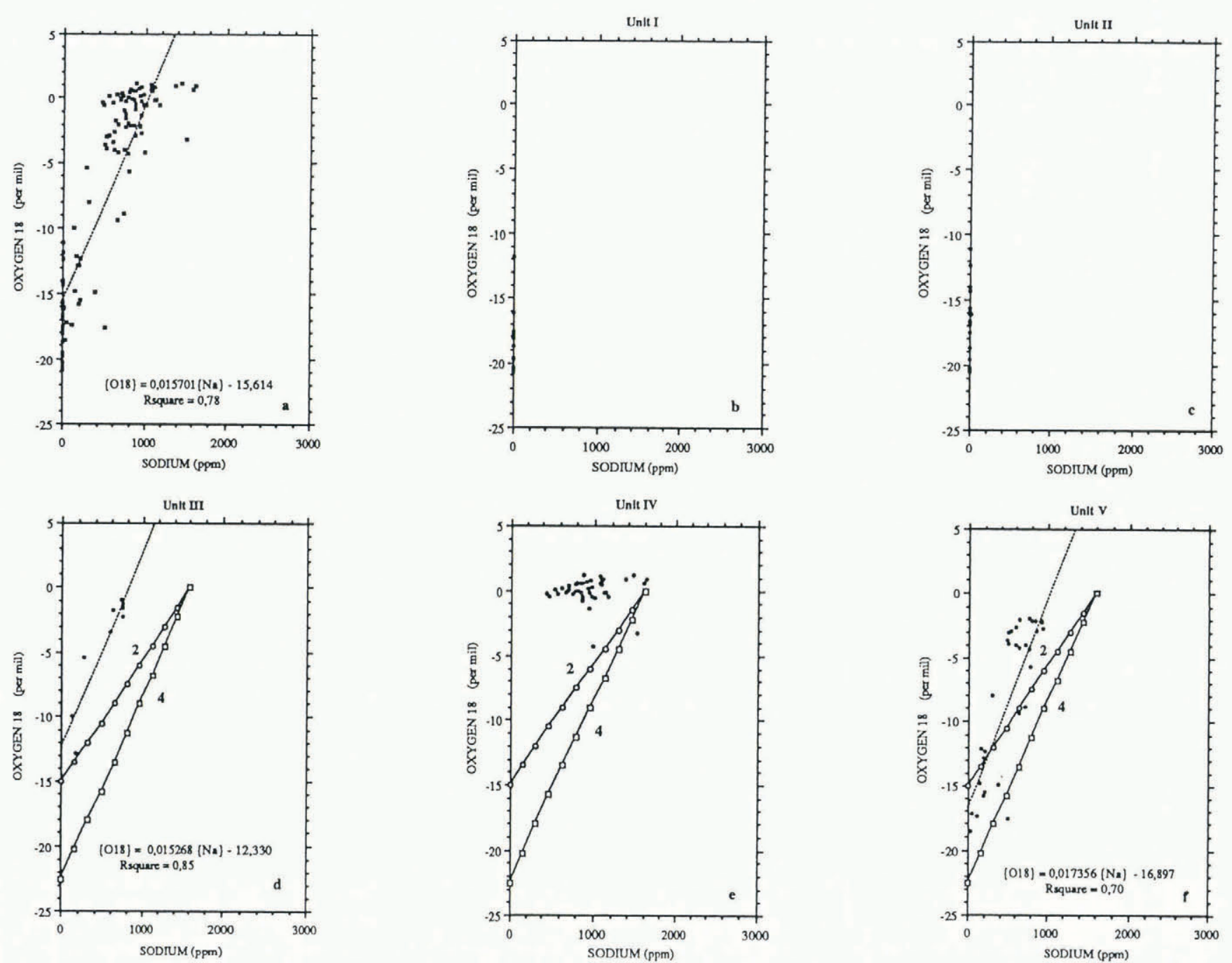

Fig. 5. $\delta^{18} \mathrm{O} / \mathrm{Na}$ diagrams for the samples from core $\mathrm{H}$. The dotted line shows the linear regression, and lines 2 and 4 correspond to those defined in Figure 8. 
b. The core presents a wide range of salinity and isotopic values. Na ranges from 0.00019 to $1.6 \%$ (e.g. global salinity ranging from 0.00062 to $5.2 \%$ o $), \delta \mathrm{D}$ from -162.5 to $8.2 \%$, and $\delta^{18} \mathrm{O}$ from -20.8 to $1.15 \%$. These ranges are comparable to those observed by Jeffries and others (1989, table II) for salinity and $\delta^{18} \mathrm{O}$, in land-fast multi-year sea ice from the Arctic, although the variability in each individual core tends to be less important in their study.

\section{Growth processes of the multi-year sea-ice cover}

Dominance of parent-water effects

A careful examination of Figure 4 reveals a fair positive correlation between the salinity and isotope profiles which is expressed by a regression coefficient of 0.78 in the $\delta^{18} \mathrm{O} / \mathrm{Na}$ diagram of Figure $5 \mathrm{a}$. This value is probably a low estimate of the strength of the correlation for two main reasons: (1) the diagram includes the samples from the top $130 \mathrm{~cm}$ of the core, which forms a special unit where the salinities are negligible and result from different genetic processes, and (2) the dispersion of the salinities for the samples displaying high isotopic values is probably due to the combined effect of a slight shift between isotopic and chemical values related to the sampling techniques, and of a higher sensitivity of the salinity signal to the inclusions of sea-water brines between frazil-ice grains, as will be discussed later.

The behaviour of $\delta^{18} \mathrm{O}$ and $\delta \mathrm{D}$ is very similar, as shown by the excellent linear regression of Figure 6a.

The two main factors which can influence the isotopic and chemical signals during a water/ice phase change in an open semi-infinite reservoir (e.g. the formation of sea ice) are: (i) the characteristics of the parent water (a "meteoric ice-sea water" mixture confined to the surface layer, in this case), and (ii) the rate of freezing. Two major sources must be considered for the fresh-water input to sea water at the sampling site: either melting of desalinated sea ice formed at a previous stage (low salinity, high $\delta$ values) or melting of snow and shelf ice (low salinity, low $\delta$ values). In the first case, progressive dilution of sea water will produce a parent water showing decreased salinities and slightly increased $\delta$ values, since sea ice is enriched in heavy isotopes with regard to sea water, and since no fractionation occurs during melting (Friedman and others, 1964; Moser and Stichler, 1980). During growth of new sea ice from this diluted parent water, a reduction in the growth rate will further enhance salt rejection from the ice and incorporation of heavy isotopes into the ice. Salinity and isotopic profiles fluctuating in opposite ways will thus be the signature of such a process. A decreasing freezing rate during growth of sea ice from undiluted sea water will give similar results, but the salinity drop will be less important. In the second case, the parent water will show decreasing salinities and decreasing $\delta$ values with increasing dilution. The freezing-rate effect will, in this case, enhance salt rejection from the new sea ice and impede the decrease of $\delta$ values. In the latter case, the maximum possible positive shifts, occurring at very low freezing rates, are $3 \%$ in $\delta^{18} \mathrm{O}$ and $20.8 \%$ in $\delta \mathrm{D}$. Thus, for dilution events higher than $10 \%$ (and this is a worst case), this process will result in salinity and isotopic profiles in sea ice fluctuating
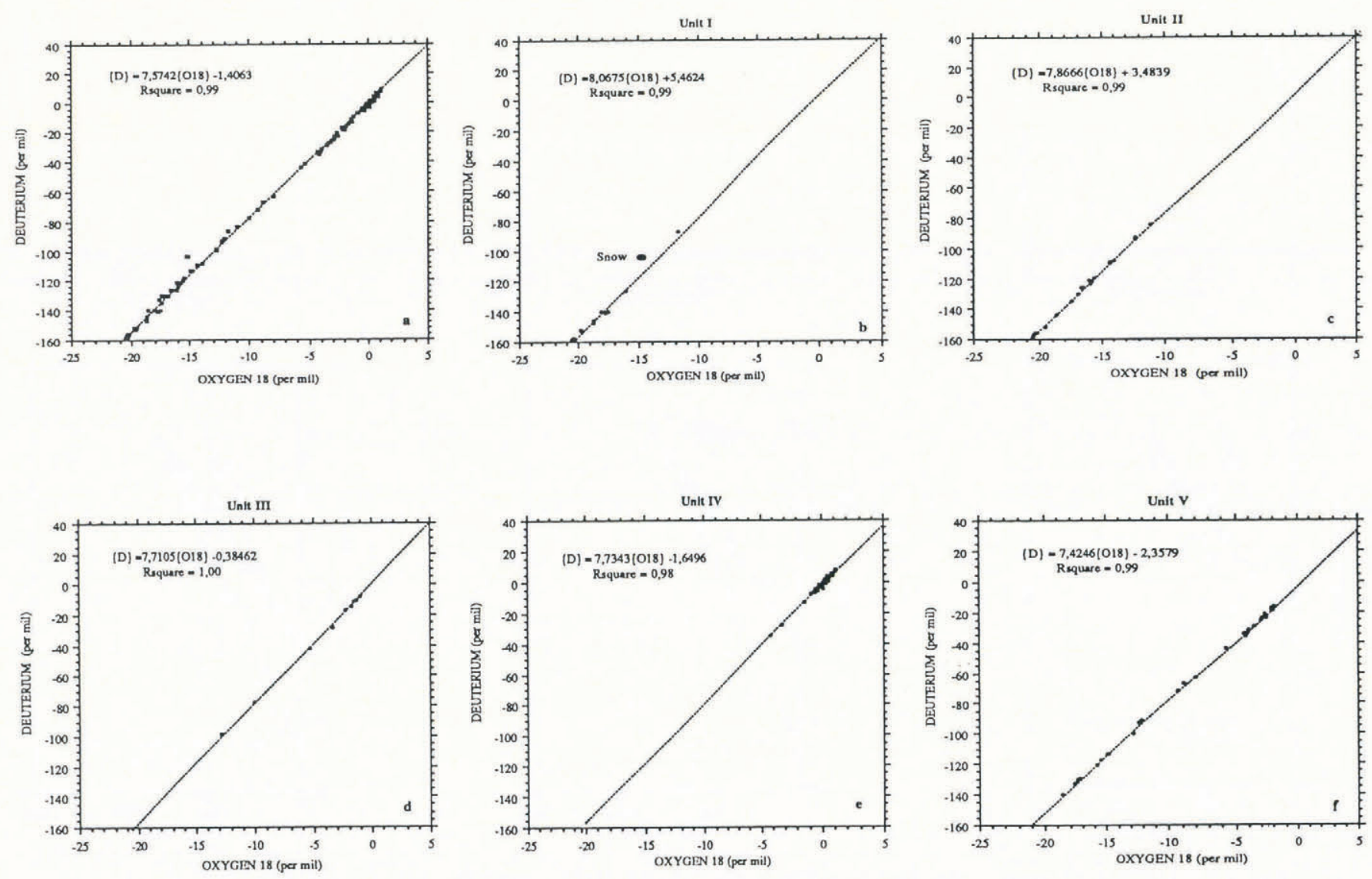

Fig. 6. $\delta D-\delta^{18} O$ diagrams for the samples from core $H$. 
in the same way. The large-scale strong positive correlation between the two curves in our core thus suggests that there were major fluctuations in the composition of the parent water during the sea-ice growth, and that this parent water results from dilution of sea water by melt from either snow or surface/basal shelf ice.

The dominance of parent-water effects over freezingrate effects can be deduced from examination of the $\delta \mathrm{D} / \delta^{18} \mathrm{O}$ diagram in Figure $6 \mathrm{a}$, where all the samples lie on a line with a slope of 7.6 (correlation coefficient of 0.999 ) and $\delta$ ranges of $170 \%$ in deuterium and $23 \%$ in oxygen-18. If we plot, on such a diagram, all the possible samples resulting from mixing of pure sea water (VSMOW) with glacial or snow meltwaters from the local environment, the points will lie on a straight line, the slope of which will be slightly lower than the value of 8.0 characteristic of the Meteoric Water Line (MWL). Using the seasonal range of co-isotopic values of the snowfalls in the rift area, typical slopes between 7.5 and 7.9 would be expected. If freezing effects are dominant, the samples could also lie on a straight line, provided that the parent water remained unchanged while the freezing rate changed significantly. The "freezing slope" would correspond to the differential fractionation during the water/ice phase changes (Jouzel and Souchez, 1982; Souchez and Jouzel, 1984). However, a much shorter range in the isotopic composition of the ice would be obtained in this case. Thus, the slope of 7.6, and the high $\delta$ ranges observed in Figure 6a, must mainly reflect the presence of a parent water with an isotopic composition evolving through time because of mixing between normal sea water and fresh meltwaters.

The marked parallelism between the salinity and isotopic curves is also an indication that flushing out of the brine by downward percolation of surface meltwaters has been very limited, because of the absence of summer melt at the top surface. In addition, the limited amount of columnar ice, which, when present, is smallgrained and lacks a brine-layer/ice-plate sub-structure, must strongly inhibit any brine-drainage process. Smallscale negative correlations between $\mathrm{Na}$ and $\delta \mathrm{D}$ have been observed in congelation ice layers from the first half of the core, possibly indicating fluctuations in the freezing rate.

Origin of the different units

Five different units can be distinguished in the core, each corresponding to a distinct process of formation. The proposed limits between the different units are marked in Figure 4 by the vertical straight lines associated with the position of a sample. To ease the comparison with data previously mentioned in the literature, we choose to use $\delta^{18} \mathrm{O}$ values in the discussion when only one isotope is considered.

Unit I (0-98 cm; Figs $5 \mathrm{~b}$ and $6 \mathrm{~b})$ resembles the surface layers of the ice shelf (Fig. 3a). It is a low-density porous medium characterized by small polygonal crystals with many voids between them and it shows two localized layers of recrystallization (type 1 ). The salinity is negligible $(0.19-4.29 \mathrm{ppm})$ and the $\delta^{18} \mathrm{O}$ values are low $(-11.8$ to $-20.8 \%$ o $)$. This unit most probably corresponds to the snow accumulation during part of the year that followed the sea-ice-cover formation (from midwinter 1987 to the end of the 1987-88 summer, when sampling occurred). The insignificant proportion of ice in the unit and the preservation of the high porosity of the medium is further evidence of the restricted surface melting in the area during the summer. It should be noted that the slope of the regression line on the $\delta \mathrm{D} / \delta^{18} \mathrm{O}$ diagram of Figure $6 \mathrm{~b}$ corresponds to the MWL (8.07).

Unit II (98-130 cm; Figs 5c and 6c) still displays a very low salinity $(2.01-7.83 \mathrm{ppm} \mathrm{Na})$ whereas the isotopic values steadily increase with depth from -20 to $-10 \%$. Small-grained columnar ice is present (the contorted fibrous-like crystals of Figure $3 \mathrm{~b}$ ) probably indicating congelation effects. However, these congelation effects must be highly localized in the profile since the slope of 7.9 (correlation coefficient of 0.998 ) shown in the $\delta \mathrm{D} / \delta^{18} \mathrm{O}$ diagram of Figure $6 \mathrm{c}$ is too high to be a freezing slope related to the decreasing freezing rate in a semi-infinite water medium with a constant isotopic value and a low salinity. The increasing isotopic values in the ice cannot be explained by an increasing share of normal sea water in the parent water, given the negligible salinities observed. Therefore, the most likely hypothesis is that this unit formed prior to unit I, and resulted from snow accumulation during the period that immediately followed the initial formation of the sea-ice cover (end of summer $1986-87$ to mid-winter 1987).

The C-shaped profile of the isotopic values from these two upper units can therefore be considered as covering the net annual snow accumulation from summer to summer, between 1.00 and $1.30 \mathrm{~m}_{\text {year }}^{-1}$, with $\delta^{18} \mathrm{O}$ values fluctuating between -11 and $-20.8 \%$. These values correspond reasonably well to those observed by Potter and others (1984) at Monteverdi Peninsula, not far from

Monteverdi Peninsula $\left(72^{\circ} 30^{\prime} \mathrm{S}, 72^{\circ} 50^{\prime} \mathrm{W}\right)$

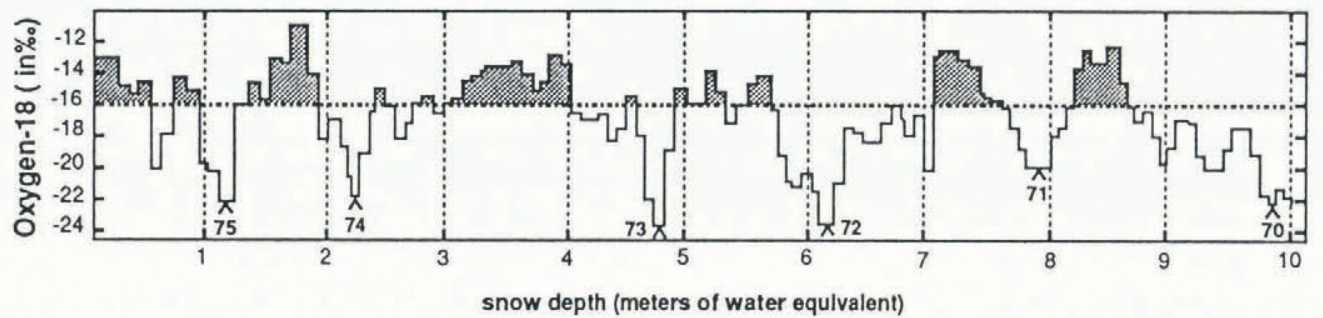

Fig. 7. Oxygen-18 profile in a $10 \mathrm{~m}$ core from Monteverdi Peninsula (data from J. G. Paren, British Antarctic Survey). The arrows mark the years and the horizontal dashed line is the mean value in $\delta^{18} \mathrm{O}$. 
the rift area, in a $10 \mathrm{~m}$ ice core (Fig. 7; data from J. Paren (personal communication)) with a mean annual accumulation of $0.95 \mathrm{~m} \mathrm{year}^{-1}$ and a range of -12 to $-22 \%$ in $\delta^{18} \mathrm{O}$. The preservation of the whole year's accumulation cycle in our core gives weight to the assertion that summer melting is very limited in the area.

A sharp transition from a $\delta^{18} \mathrm{O}$ value of $-13 \%$ to a value of $0 \%$ marks the beginning of unit III (130$175 \mathrm{~cm}$; Figs $5 \mathrm{~d}$ and $6 \mathrm{~d}$ ). The linear regressions for $\delta \mathrm{D} / \delta^{18} \mathrm{O}$ (slope of 7.7 with $r^{2}=1.0$ ) and $\delta^{18} \mathrm{O} / \mathrm{Na}$ $\left(r^{2}=0.85\right)$ clearly indicate the dominance of parentwater effects over freezing-rate effects.

Three main sources of fresh water to dilute the normal sea water can be proposed:

a. Melting of first-year sea ice from the previous year.

b. Melting of snow falling on the surface of the ice shelf and in the open sea water during the summer.

c. Melting of bottom shelf ice.

Extensive melting of first-year sea ice from the previous year is highly improbable since most of the rift is covered with thick multi-year ice, with the exception of the restricted areas where depressions cross and open sea water forms during the summer. Also, mixing of melted sea ice with sea water would result in salinity and isotopic profiles fluctuating opposite ways in the new sea ice formed, as discussed above.

Surface melt on the ice shelf during the summer is a possible source of fresh water. However, as discussed previously and as attested by summer aerial photographs, by annual mean temperatures estimated on Monteverdi Peninsula or Spaatz Island (Peel and Clausen, 1982) and by British Antarctic Survey travelling reports, surface melting is probably much more limited here than in the northern part of the ice shelf (between $70^{\circ} 30^{\prime}$ and $72^{\circ} \mathrm{S}$; Potter and others, 1984). Nevertheless, if the hypothesis proposed for the formation of unit II is valid, partial dilution of surface sea water by snow falling in open waters should be considered. Potter and others (1984) calculated a mean $\delta^{18} \mathrm{O}$ value of $-15.0 \pm 0.9 \%$ for ice-shelf accumulation in the southern part of George VI Sound. This corresponds fairly well with the values of -15.10 and $-15.20 \%$ measured in fresh snow from two different precipitation events on the sampling site at the end of the summer (March 1988). Surface melting will only occur during the summer season and will mainly affect the more positive values of the annual accumulation cycle, as shown by the flatness of the summer peaks (above the mean) in the isotopic records of Figure 7. The meltwater that will eventually reach the sea-ice/sea-water interface will thus display isotopic values ranging between -12 and $-16^{\circ} \%$ in $\delta^{18} \mathrm{O}$. A value of $-15 \%$ will therefore be considered as typical of the melt either from the accumulation occurring at the surface of the ice shelf or from the snow falling in the open waters in the area.

The isotopic value of the melt from the base of the ice shelf is much more difficult to estimate. Potter and others (1984) used a mean $\delta^{18} \mathrm{O}$ value of $-22.5 \pm 0.4^{\circ} \%$ for the ice flux into the southern part of the ice shelf from the inland ice sheet, estimated from an equilibrium mass and isotope balance partly using the temperature $/ \delta^{18} \mathrm{O}$ relationship established by Peel and Clausen (1982) for the Antarctic Peninsula. We shall assume that this value can be used as the average $\delta^{18} \mathrm{O}$ for ice at the base of the ice shelf.

Using the salinity value of $34.72 \%(10.67 \%$ in $\mathrm{Na})$ and the $\delta^{18} \mathrm{O}$ value of $+0.16 \%$ proposed by Potter and others (1984) for Warm Deep Water (WDW), the two mixing lines respectively of surface and basal meltwaters with WDW can be calculated. In both cases, we can discriminate between fresh ( $<0.5 \%$ global salinity), brackish $(0.5-17 \%)$ and sea water $(>17 \%)$ as proposed by Jeffries and others (1989).

Reconstruction of the $\mathrm{Na} / \delta^{18} \mathrm{O}$ profile in the ice formed by freezing of these waters is complicated by nonequilibrium processes connected with fluctuations of the growth rates and by possible inclusion of liquid in the growing ice (Souchez and Jouzel, 1984; Souchez and others, 1987, 1988). However, by using a method similar to that of Jeffries and others (1989), a broad envelope of possible values can be obtained by applying minimum and maximum apparent fractionation coefficients for $\mathrm{Na}$ and $\delta^{18} \mathrm{O}$. For $\delta^{18} \mathrm{O}$, extremely low freezing rates will allow the maximum equilibrium fractionation to occur with a positive shift of $3 \%\left(\alpha=1000+\delta_{\mathrm{i}} / 1000+\delta_{\mathrm{o}}=\right.$ 1.003 , where $\delta_{\mathrm{i}}$ and $\delta_{\mathrm{o}}$ are the $\delta$ values for ice and water respectively (O'Neil, 1968)), and fast freezing will not yield any apparent fractionation. The effect of sea-water inclusions on the isotopic signal of sea ice can be considered as negligible, as shown by Tison and Haren (1989). Na-incorporation factors $\left(S_{\mathrm{i}} / S_{\mathrm{o}}\right.$, where $S_{\mathrm{i}}$ and $S_{\mathrm{o}}$ are the salinity for ice and water, respectively) as low as 0.040.05 have been observed at the bottom of first-year sea ice by Souchez and others (1988) and a maximum value of about 0.15 , as observed in our core, should cover most of the observations quoted in the literature. This wide range of salinity-fractionation factors is also thought to cover any alteration of the signal by sea-water inclusions in the ice.

Figure 8 shows the four mixing lines obtained in the ice by applying the extreme values of the fractionation coefficients in $\mathrm{Na}\left(S_{\mathrm{i}} / S_{\mathrm{o}}\right)$ and in oxygen-18 $(\alpha)$ to the two water-mixing lines calculated above. The sample values are displayed in the background. The percentage of WDW varies from 100 to $0 \%$ along each mixing line. Curves 1 and 2 correspond to dilution of normal sea water by meltwaters from the surface of the ice shelf and curves 3 and 4 to dilution by meltwaters from the base of the ice shelf. Only curves 2 and 4 have been drawn on Figure $5 d$, e and $\mathrm{f}$, since curves 1 and 3 are very close to the ordinate axis and are therefore not relevant in distinguishing the various parent-water sources.

All the points from unit III lie above the two mixing lines in Figure 5d. This implies that these ice samples could either have resulted from the freezing of sea water diluted by surface meltwaters (with fresh-water proportions ranging between 10 and $90 \%$ ) and/or from the freezing of sea water diluted by meltwaters from the base of the ice shelf (between 10 and $50 \%$ of fresh water).

Unit IV (175-452 cm; Figs 5e and 6e) is the thickest unit in the core. It is characterized by the stabilization of $\mathrm{Na}$ and $\delta^{18} \mathrm{O}$ around mean values of respectively $0.9 \%(900 \mathrm{ppm})$ and $0 \%$. However, it is clear in Figure 4 that five major large-scale sympathetic fluctuations of 


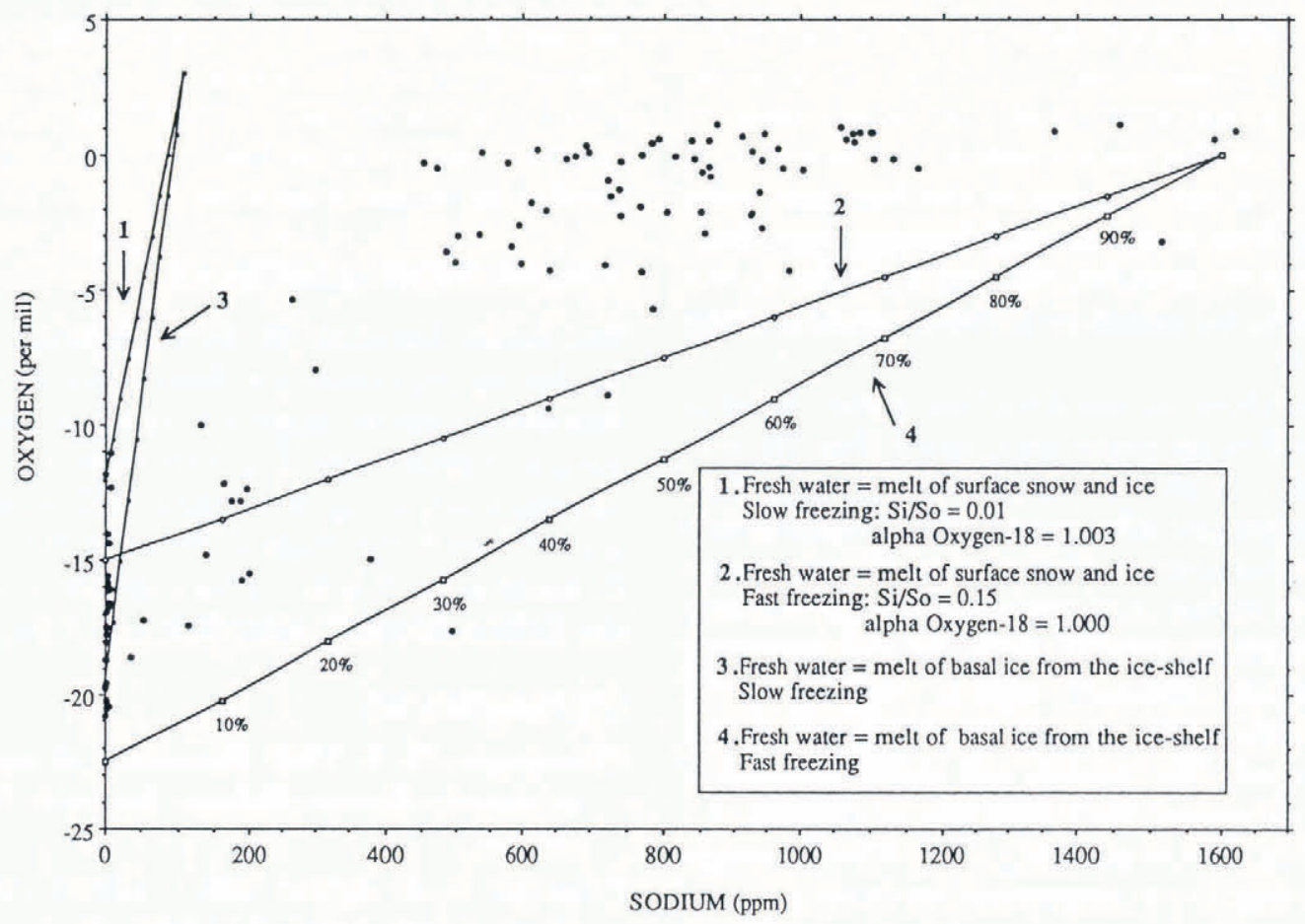

Fig. 8. Mixing lines for ice formed by freezing of sea water diluted by fresh water from surface or basal melting of the ice shelf and for extreme values of the fractionation coefficients. The percentage represents the proportion of normal sea water in the mix.

$\mathrm{Na}$ and $\delta^{18} \mathrm{O}$ characterize the unit, with minimum values at depths of 223, 258,290,330 and $390 \mathrm{~cm}$ (dashed lines in Figure 4). It should be noted that this sympathetic response between $\mathrm{Na}$ and $\delta^{18} \mathrm{O}$ does not show up as a good correlation in the $\delta^{18} \mathrm{O} / \mathrm{Na}$ diagram of Figure 5e. This is probably the expression of a different sensitivity of the chemical and isotopic signals to the liquid water inclusions during accretion of individual frazil-ice crystals at the bottom of the pre-existing ice cover. Since at least $85 \%$ of the salts are rejected from the sea-ice crystals as they form, slight fluctuations in the amount of parent water entrapped between the crystals as they accumulate at the base of the ice cover may cause important variations in the measured salinity in the core. This effect is negligible for the isotopic signal (Tison and Haren, 1989), since most of the signal results from the crystal itself. Thus, at two different locations in the core, similar changes in the isotopic signal will correspond to chemical changes of the same sign but of different intensity.

Most of the samples in unit IV could result from the freezing of sea water diluted by fresh water from each of the two possible sources, the proportion of freshwater input being a few per cent (maximum $20-30 \%$ in two-point samples at depths of 223 and $258 \mathrm{~cm}$, both corresponding to columnar ice; Fig. 4). However, two arguments indicate a sub-ice-shelf origin. First, units I and II correspond to the snow accumulation of a whole year with limited melting during the summer and unit III results from the freezing of normal sea water which was less and less diluted by fresh water in the course of time. This last unit was therefore growing downward at the same time that unit II was piling up, at the beginning of the winter following the initial sea-ice-cover formation. This implies that unit IV formed during the winter, when any surface melting is precluded. Secondly, one of the two stronger dilution peaks is located below the two mixing lines (Fig. 5e) and therefore could only be produced by fresh water with a $\delta^{18} \mathrm{O}$ value lower than $-22.5 \%$. This could only be provided by melting at the base of the ice shelf.

Although dilution events are not always associated with textural differences (see, for example, the event at $390 \mathrm{~cm}$ ), it should be noted that the only occurrence of platelet ice (Fig. 3d) is located around two of the main dilution peaks (at 290 and $330 \mathrm{~cm}$ ). Platelet ice is a special type of frazil ice usually associated with adiabatic expansion of sea water as it ascends from beneath ice shelves (see, for example, Robin, 1979; Lange and others, 1989). If dilution occurs at the bottom of the ice shelf, it is therefore not surprising to trace it in the chemistry of the platelet ice in the core.

At $450 \mathrm{~cm}$ depth, the isotopic and chemical values drop sharply (from 741 to $190 \mathrm{ppm}$ in $\mathrm{Na}$ and from -0.25 to $-15.75^{\circ} \%$ in $\left.\delta^{18} \mathrm{O}\right)$; and a fifth unit of alternate columnar (Fig. 3e) and granular ice (Fig. 3f) occurs (unit V $(452-553 \mathrm{~cm}$; Figs $5 \mathrm{f}$ and $6 \mathrm{f})$ ) partly showing the characteristics of ice resulting from the freezing of brackish water. About one-third of the samples from this unit can only be formed by freezing of waters resulting from the mixing of normal sea water with meltwaters from the base of the ice shelf, as indicated by Figure 5f. Dilution percentages as high as $80 \%$ fresh water $/ 10 \%$ sea water can be observed. Contacts between individual grains are sharper and better defined than in the more saline units above (Fig. 3f). The higher dilutions correspond to the frazil-ice layers that must therefore have been formed at depth, not far from the production zone, thus freezing- 
in the chemical and isotopic signature of the fresh water before significant mixing with the normal sea water occurred. However, the presence of considerable amounts of columnar ice in this unit seems to indicate that it partly forms by direct freezing of the brackish water layer at the bottom of the ice cover (congelation ice). The absence of brine-layer/ice-plate sub-structure in this columnar ice (Fig. 3e) might be a trademark of brackish congelation ice.

Isotopic and chemical profiles of sea water, down to $15 \mathrm{~m}$ (collected through boreholes G and I (Fig. 2)), confirm the sub-shelf origin for the fresh water. The water samples were taken just after coring, while a considerable number of equigranular small frazil crystals were regularly floating up to the open-water surface of the borehole. These frazil-ice crystals were sampled separately and yielded isotopic values of -4.55 to $-5.90 \%\left(\delta^{18} \mathrm{O}\right)$ and -33 to $-46 \%$ ( $\delta \mathrm{D})$, at sites $\mathrm{G}$ and I respectively. Under the ice cover, the isotopic and chemical values of the sea water are around $8000-8500 \mathrm{ppm}$ of sodium, -1.1 to $-1.8 \%\left(\delta^{18} \mathrm{O}\right)$ and -8 to $-13 \%$ o $(\delta \mathrm{D})$. These isotopic values are too high to be responsible for those observed in the frazil ice at the extreme base of the core $(-2 \%$ in $\delta^{18} \mathrm{O}$ and $-19 \%$ in $\left.\delta \mathrm{D}\right)$, whatever the freezing rate. Similarly, the individual frazil-ice crystals accumulating at the surface need a parent water with isotopic values fluctuating between -66 and $-33 \%$ in $\delta \mathrm{D}$ and -9 to $-4 \%$ in $\delta^{18} \mathrm{O}$. Such water was not observed under the seaice cover and must result from the mixing of normal sea water with meltwaters from the base of the ice shelf. The top of unit $\mathrm{V}$ therefore marks an increasing production of meltwater at the base of the ice shelf, probably at the beginning of the austral summer 1987-88.

\section{CONCLUSION}

The major rifts developing in the southern part of George VI Sound, where the ice shelf calves into huge tabular icebergs, are ideal traps for the water masses ascending in front of the ice shelf. These contribute to the accretion of sea ice at the open surface between the sides of the rift. Combined salinity and isotopic profiles of this sea ice allow the origin of the parent water to be traced. Results from a detailed profile of a $5.54 \mathrm{~m}$ thick ice core sampled in the area show that it is probably second-year sea ice that has survived one melt season (Weeks and Ackley, 1986). Half of the core consists of sea ice, following the Jeffries and others (1989) terminology, formed in the winter. Although, during this period, the parent water is close to normal sea water, the $\mathrm{Na}$ and $\delta^{18} \mathrm{O}$ curves show a few sympathetic large-scale fluctuations indicating dilution events reaching $20 \%$ of fresh-water input that might reflect small variations in the basal melting of the ice shelf. A sharp transition from sea ice to brackish ice $(450 \mathrm{~cm}$ depth), that must result from mixing with meltwater from basal shelf ice, indicates the importance of this process during the summer period, with maximum dilution coefficients up to $80 \%$ of fresh water. Winter accretion consists almost exclusively of frazil-ice production, while summer accretion alternates between frazil ice formed at depth close to the fresh-water-input location (low-salinity and low-isotopic signal) and congelation ice formed by direct progression of a freezing front under the sea-ice cover into a less-diluted parent water. Further work on the multi-year sea ice formed in the rift area will aim to produce a semi-quantitative estimate of the fresh-water output from the base of George VI Ice Shelf at its southern ice front.

\section{ACKNOWLEDGEMENTS}

The British Antarctic Survey is gratefully acknowledged for having supported the field work in the Antarctic Peninsula. Special thanks are due to J. Hall for his efficiency in organizing field operations and J. Pailthorpe for his help in collecting the samples. J.-L.T. is a "Chercheur Qualifié" with the Belgian National Scientific Research Foundation (F.N.R.S.). This paper is a contribution to the Belgian scientific programme in Antarctica.

\section{REFERENCES}

Cherepanov, N. V. 1966. Structure of sea ice of great thickness. Ottawa, Defense Research Establishment. (T448R.)

Friedman, I., B. Schoen and J. Harris. 1961. The deuterium concentration in Arctic sea ice. J. Geophys. Res., 66(6), 1861-1864.

Friedman, I., A. C. Redfield, B. Schoen and J. Harris. 1964. The variation of the deuterium content of natural waters in the hydrological cycle. Rev. Geophys., 2, 177-189.

Gow, A. J. and S. Epstein. 1972. On the use of stable isotopes to trace the origins of ice in a floating ice tongue. J. Geophys. Res., 77(33), 6552-6557.

Gow, A. J., S. F. Ackley, K. R. Buck and K. M. Golden. 1987a. Physical and structural characteristics of Weddell Sea pack ice. CRREL Rep. 87-14.

Gow, A. J., W. B. Tucker, III and W. F. Weeks. 1987b. Physical properties of summer sea ice in the Fram Strait, June-July 1984. CRREL Rep. 87-16.

Jeffries, M. O., H. R. Krouse, W. M. Sackinger and H. V. Serson. 1989. Stable-isotope $\left({ }^{18} \mathrm{O} /{ }^{16} \mathrm{O}\right)$ tracing of fresh, brackish and sea ice in multi-year land-fast sea ice, Ellesmere Island, Canada. J. Glaciol., 35(119), 9-16.

Jouzel, J. and R. A. Souchez. 1982. Melting-refreezing at the glacier sole and the isotopic composition of the ice. J. Glaciol., 28(98), 35-42.

Lange, M. A., S.F. Ackley, P. Wadhams, G.S. Dieckman and H. Eicken. 1989. Development of sea ice in the Weddell Sea. Ann. Glaciol., 12, 92-96.

Lyons, J. B., S. M. Savin and A. J. Tamburi. 1971. Basement ice, Ward Hunt Ice Shelf, Ellesmere Island, Canada. J. Glaciol., 10(58), 93-100.

Meese, D. A. 1989. The chemical and structural properties of sea ice in the southern Beaufort Sea. CRREL Rep. 89-25.

Moser, H. and W. Stichler. 1980. Environmental isotopes in ice and snow. In Fritz, P. and J. C. Fontes, eds. Handbook of environmental isotope geochemistry. Vol. 1. New York, Elsevier, 141-178.

O'Neil, J.R. 1968. Hydrogen and oxygen isotope fractionation between ice and water. J. Phys. Chem., 72(10), 3683-3684.

Peel, D. A. and H. B. Clausen. 1982. Oxygen-isotope 
and total beta-radioactivity measurements on $10 \mathrm{~m}$ ice cores from the Antarctic Peninsula. J. Glaciol., 28(98), 43-55.

Potter, J. R., J. G. Paren and J. Loynes. 1984. Glaciological and oceanographic calculations of the mass balance and oxygen isotope ratio of a melting ice shelf. J. Glaciol., 30(105), 161-170.

Riley, J.P. and G. Skirrow. 1965. Chemical oceanography. New York, Academic Press.

Robin, G. de Q. 1979. Formation, flow, and disintegration of ice shelves. J. Glaciol., 24(90), 259-271.

Schwarzacher, W. 1959. Pack-ice studies in the Arctic Ocean. J. Geophys. Res., 64(12), 2357-2367.

Souchez, R. and J. Jouzel. 1984. On the isotopic composition in $\delta \mathrm{D}$ and $\delta^{18} \mathrm{O}$ of water and ice during freezing. J. Glaciol., 30(106), 369-372.

Souchez, R., J.-L. Tison and J. Jouzel. 1987. Freezing rate determination by the isotopic composition of the ice. Geophys. Res. Lett., 14(6), 599-602.

Souchez, R., J.-L. Tison and J. Jouzel. 1988. Deuterium concentration and growth rate of Antarctic first-year sea ice. Geophys. Res. Lett., 15(12), 1385-1388.

Tison, J.-L. and J. Haren. 1989. Isotopic, chemical and crystallographic characteristics of first-year sea ice from Breid Bay (Princess Ragnhild Coast - Antarctica). Antarct. Sci., 1(3), 261-268.

Weeks, W. F. and S. Ackley. 1986. The growth, structure, and properties of sea ice. In Untersteiner, N., ed. The geophysics of sea ice. New York, Plenum Press, 9164. (Nato ASI Series, Series B, Physics, 146.)

The accuracy of the references in the text and in this list is the responsibility of the authors, to whom queries should be addressed.

MS received 12 November 1990 and in revised form 24 May 1991 